\title{
OPEN Deforestation is the turning point for the spreading of a weedy epiphyte: an IBM approach
}

\author{
Cleber Juliano Neves Chaves ${ }^{1,2 \bowtie}$, Bárbara Simões Santos Leal ${ }^{1,2}$, Davi Rodrigo Rossatto ${ }^{3}$, \\ Uta Berger ${ }^{4}$ \& Clarisse Palma-Silva ${ }^{2}$
}

The rapid spread of many weeds into intensely disturbed landscapes is boosted by clonal growth and self-fertilization strategies, which conversely increases the genetic structure of populations. Here, we use empirical and modeling approaches to evaluate the spreading dynamics of Tillandsia recurvata (L.) L. populations, a common epiphytic weed with self-reproduction and clonal growth widespread in dry forests and deforested landscapes in the American continent. We introduce the TRec model, an individual-based approach to simulate the spreading of $T$. recurvata over time and across landscapes subjected to abrupt changes in tree density with the parameters adjusted according to the empirical genetic data based on microsatellites genotypes. Simulations with this model showed that the strong spatial genetic structure observed from empirical data in $T$. recurvata can be explained by a rapid increase in abundance and gene flow followed by stabilization after ca. 25 years. TRec model's results also indicate that deforestation is a turning point for the rapid increase in both individual abundance and gene flow among $T$. recurvata subpopulations occurring in formerly dense forests. Active reforestation can, in turn, reverse such a scenario, although with a milder intensity. The geneticbased study suggests that anthropogenic changes in landscapes may strongly affect the population dynamics of species with 'weedy' traits.

Intensive disturbances are inherent to human history and have substantial effects on natural communities ${ }^{1}$. Ecosystems are currently subjected to unprecedented rates of human-induced changes that are fostering the sixth mass extinction ${ }^{2}$. However, not all organisms respond the same way to human disturbances. While many species become extinct or migrate, others thrive in anthropogenic environments and can invade natural environments ${ }^{3,4}$. Indeed, human activities, such as those related to deforestation, have allowed the dispersal and reproduction of many species ${ }^{4}$. Weeds are opportunistic species that can evolve from introduced or native species that grow within human-transformed landscapes without being cultivated and negatively affecting both the environment and the economy ${ }^{1,5,6}$.

Between 50 and $80 \%$ of all invasive plant species can be classified as weeds, depending on current impacts and human perception ${ }^{6}$. However, native species possessing traits that pre-adapt them to establish in newly disturbed areas can also evolve into weeds ${ }^{7}$. In addition to landscape disturbances, propagule pressure, and individual density, the spreading rate of weeds is mainly driven by their high dispersal abilities and wide traits' plasticity, which have enabled them to rapidly colonize large areas ${ }^{5,8-11}$. In particular, clonal growth and self-fertilization (hereafter referred to as 'selfing') are some of the most important adaptations that allow weeds to establish new populations after long-distance dispersal events ${ }^{12,13}$. Indeed, clonal growth and selfing favor invasiveness and weediness, even in native species, by mitigating the Allee effect of small populations and, therefore, enhance reproductive assurance and genetic transmission ${ }^{14-16}$. While selfing can increase species' investment in seed production, clonal growth reduces the likelihood of genet death by sharing stochastic risk over multiple ramets ${ }^{17,18}$.

Despite the positive effect of clonal growth and selfing strategies on weed invasiveness, the aggregation of selffertilized offspring and clonal individuals strongly influences the spatial genetic structure (SGS) of populations, reducing local genetic diversity and promoting inbreeding depression ${ }^{18-22}$. On the other hand, clonal growth may also lead to the maintenance of (once established) genetic diversity ${ }^{23,24}$, while continuous selfing can result in the absence of inbreeding depression as a consequence of purging of deleterious alleles over generations ${ }^{16,25,26}$.

${ }^{1}$ Programa de Pós-Graduação em Ecologia e Biodiversidade, Instituto de Biociências, Universidade Estadual Paulista, Rio Claro 13506-900, Brazil. ²Departamento de Biologia Vegetal, Instituto de Biologia, Universidade Estadual de Campinas, Campinas 13083-862, Brazil. ${ }^{3}$ Departamento de Biologia, Universidade Estadual Paulista, Jaboticabal 14884-900, Brazil. ${ }^{~ I n s t i t u t e ~ o f ~ F o r e s t ~ G r o w t h ~ a n d ~ C o m p u t e r ~ S c i e n c e s, ~ T e c h n i s c h e ~ U n i v e r s i t a ̈ t ~ D r e s d e n, ~}$ 01737 Tharandt, Germany. ${ }^{\boxplus}$ email: cleberchaves@gmail.com 
These effects lead to a strong population subdivision, creating a metapopulation dynamic with extinction in a site being balanced by recolonization. This dynamic may, therefore, favor selfing and clonal genotypes, due to their higher capacities of recolonization ${ }^{20,27}$.

Understanding local spread dynamics is essential to elucidate how native weeds opportunistically reach broad range distributions, despite their tendency to form highly aggregated populations with low genetic diversity. Individuals within populations with reduced abundance and limited seed dispersal, for instance, are usually close-related at the beginning of colonization ${ }^{28}$. With an increase in abundance after colonization, the general kinship often reduces due to the greater overlapping of maternal seed shadows and successive introductions of new genotypes through seed dispersal from neighbor populations ${ }^{28,29}$. Therefore, we expect that density-relatedness dynamics reduce the high SGS of populations of selfing and clonal species throughout colonization stages ${ }^{28,30,31}$.

Deforestation is another key factor for native weeds to fasten their colonization and form abundant populations into newly disturbed landscapes ${ }^{32-34}$. Oppositely, we also expect that coordinated actions of reforestation, or afforestation, should be an efficient strategy to control the weed spreading. Here, we integrate empirical and simulated genetic data to study the spreading dynamics of Tillandsia recurvata (L.) L., an epiphytic weedy bromeliad with selfing and clonal growth strategies, widely distributed in the American continent ${ }^{35-37}$. This species is known by several popular names (e.g., ball-moss, Jamaican ball moss, musgo de bola, heno de bola, galinita, and cravo-do-mato), which refer to the dry aspect of leaves and the intense clonal growth from leaf axils that forms a "ball-like" shape ${ }^{38}$ (see Fig. S1). The high abundance and dominance of T. recurvata in epiphytic communities constitute a characteristic feature of open landscapes from Argentina to the southern United State ${ }^{38,39}$ and have long attracted the interest of naturalists and ecologists ${ }^{38,40-42}$. Studies have described T. recurvata as the most xerophytic species among the tropical and subtropical epiphytes ${ }^{43,44}$, with "...probably the greatest adaptability of any plant in the Western Hemisphere..." ${ }^{4}$. Several ecological and reproductive features, such as small size, absorbent leaf scales, CAM photosynthesis, wind-dispersed seeds, the spontaneous self-pollination underpinning its tiny cleistogamous flowers, and intense clonal growth have allowed T. recurvata to form dense populations even on isolated trees within recently disturbed landscapes ${ }^{46-48}$. As an epiphytic weed, populations of T. recurvata develop on landscape in which each host tree performs as an isolated patch of habitat scattered in a harsh matrix ${ }^{49,50}$, determining that the majority of dispersed seeds of $T$. recurvata fall close to the mother and establish on the same host tree ${ }^{51-53}$.

The high adaptability of $T$. recurvata has fostered the species distribution in human-disturbed regions, forming large populations in urban landscapes, actively growing on fences and electric light wires ${ }^{54,55}$. Such great abundance and population density have led some authors to consider T. recurvata as an "epiphytic weed," describing herbicides and other techniques to control its spreading ${ }^{35,36}$. Although T. recurvata cannot be classified as a parasite, studies have listed deleterious effects that massive populations may have on co-occurring epiphytes and host trees, as it competes for light with new shoots, modifies barks, and affects seedling growth ${ }^{38,42}$. Therefore, the reproductive biology, clonal growth, and opportunistic behavior of T. recurvata make this species a good model species for studying the temporal and spatial spreading dynamics of weeds.

Here, we specifically aimed to investigate (I) whether subpopulations of T. recurvata growing on neighbor trees of an anthropic landscape are genetically structured; as it occurs, we then tested (II) how such genetic structuring develops over time and varies in landscapes with distinct tree densities; and (III) whether abrupt human-induced changes in the landscape (deforestation or reforestation) affect the dynamics of T. recurvata. We hypothesize that $T$. recurvata exhibits high spatial genetic structure due to intrinsic features, such as clonal growth, selfing, and epiphytic habit. Such genetic structuring, however, might be reduced as subpopulations become denser and more connected by seed dispersal. Since this species is drought-adapted and its seeds are wind-dispersed, we also hypothesize that reductions in tree densities (i.e. deforestation) will lead to increased individual abundances and reduced genetic structure among subpopulations on trees.

To achieve our goals and properly test the outlined hypothesis we might gather numerous and continuous empirical genetic data over a long period in similar landscapes with varying tree densities, which would be intractable and very time consuming ${ }^{56}$. To overcome this difficulty, we adopted a modeling approach, which has been helpful to simulate spatio-temporal dynamics of species genetic structure in natural systems ${ }^{57,58}$. We introduce the TRec model, which takes advantage of the individual-based models (IBMs) by explicitly incorporating characteristics of each individual (e.g., life stage, size, and genotype) and simulating interactions among them and with the surroundings in multiple landscapes, which may produce complex and distinct outcomes ${ }^{59}$. In the study presented, we employed the combined results from microsatellite markers and the TRec model to estimate and simulate the SGS of a T. recurvata population scattered on neighboring trees and to understand the emergence of the observed empirical patterns of genetic variation over colonization time and across landscapes with distinct tree densities.

\section{Results}

Empirical genetic diversity and structure. The empirical data was collected in a human-transformed landscape of ca. 0.2 ha in southwest Brazil $\left(-21.244289^{\circ} \mathrm{S},-48.300486^{\circ} \mathrm{W}\right)$ composed by a grove of 20 cultivated Handroanthus spp. (Bignoniaceae) of similar ages (ca. 20 years) apart from each other from 2.5 to $47.5 \mathrm{~m}$ and surrounded by a grassland matrix (ca. 100 tree/ha; Fig. 1). Based on seven microsatellite loci genotyped in a total of 224 individuals of T. recurvata hosted on 14 distinct trees (considered here as subpopulations), we observed moderate levels of genetic diversity within subpopulations, despite high endogamy and generally high genetic structure. The number of alleles (A) per subpopulation ranged from 19 to 30, while allelic richness $\left(A_{R}\right)$ ranged from 2.20 to 3.54 , and the number of private alleles $\left(A_{P}\right)$ was up to 2 per subpopulation (see Table $S 1$ in Appendix S2). Expected $\left(\mathrm{H}_{\mathrm{E}}\right)$ and observed $\left(\mathrm{H}_{\mathrm{O}}\right)$ heterozygosities per subpopulation ranged from 0.27 to 0.51 , and from zero to 0.20 , respectively (Table $S 1)$. The inbreeding coefficients $\left(F_{\text {IS }}\right)$ were significant and very 


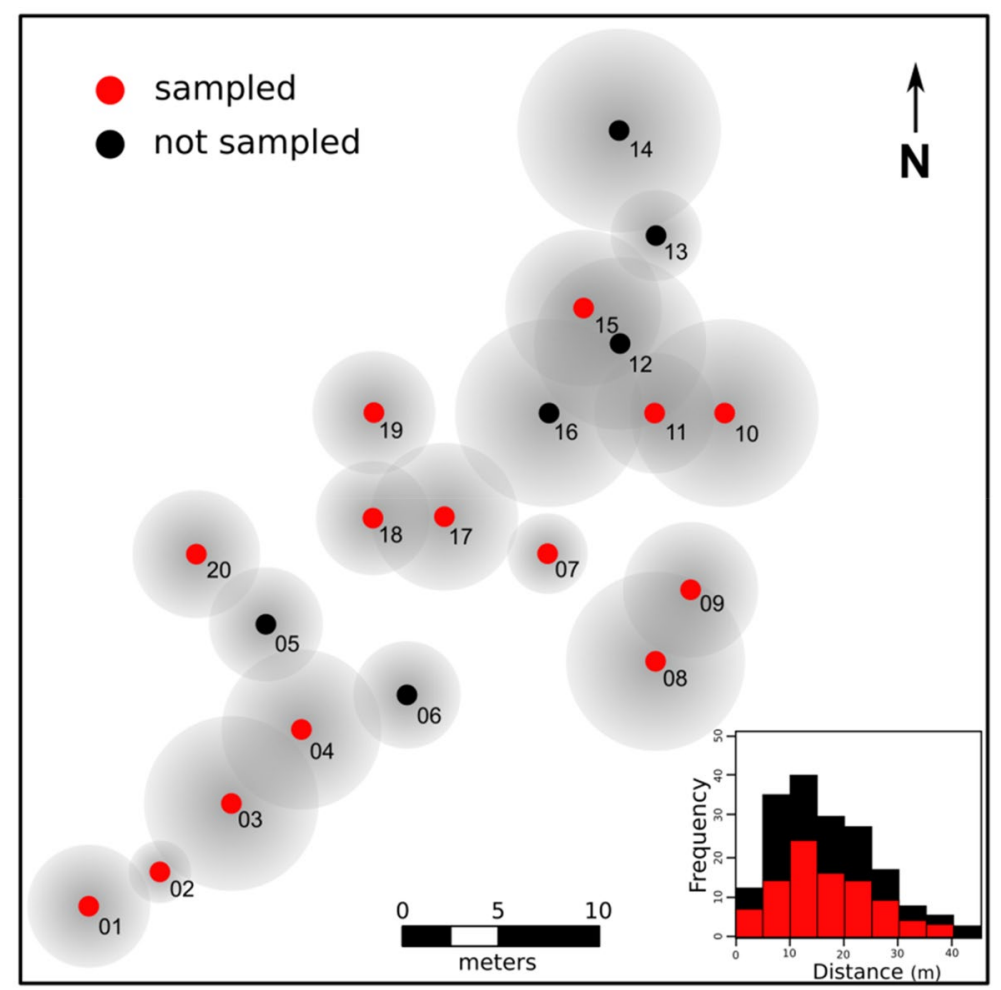

Figure 1. Spatial distribution and histogram of the frequency of distance classes of pairwise trees within the studied landscape. Numbers refer to IDs of trees hosting the Tillandsia recurvata populations analyzed. Gray circles around each dot are representations of the crown area of each tree. Red dots and bars represent, respectively, the location and frequency of distances among pairs.

high in all sampled subpopulations, ranging from 0.52 to 1.0 , due to significant heterozygosity deficit under Hardy-Weinberg equilibrium (Table S1). Pairwise subpopulation differentiation $\left(F_{\text {ST }}\right)$ ranged from 0.01 to 0.31 (Fig. S1). The Mantel test indicated a significant although weak isolation-by-distance (IBD) pattern among subpopulations only when using Edward's genetic distances $(r=0.243 ; p=0.032)$. AMOVA analysis, in turn, showed lower genetic variance among subpopulations (17.26\%) than within subpopulations $(82.74 \%)$ although it was significantly greater than zero $(p<0.001)$.

The highest kinship $\left(\mathrm{F}_{\mathrm{ij}}\right)$ was detected at the smallest distance interval (up to $2.5 \mathrm{~m}$ ), which is significantly higher than expected by chance ( $p<0.05$; Fig. 2A). Kinship coefficients peaked outside the $95 \%$ confidence interval at almost all distance classes, showing a remarkable decay at three out of four distance classes higher than ca. $13 \mathrm{~m}$ (Fig. 2A), and a significant spatial genetic structure $\left(\mathrm{S}_{\mathrm{p}}=0.024 ; p<0.001\right)$. We detected turnovers of alleles and multi-locus genotype (MLG) of 0.031 and 0.537 , respectively. MLGs were evenly spaced among subpopulations, generally with few shared and one distinct dominant MLG in most of the subpopulations (Fig. 2B).

TRec model setting. The TRec model simulates the colonization of a landscape by multiple T. recurvata seeds with random multi-locus genotypes (MLG) that thrive on scattered trees (Fig. 3; see Appendix S1 for a detailed description of the model). The sensitivity test of the five varying parameters adopted in the TRec model (Fig. S3) showed that, in general, high rates of mutation and seed germination can significantly decrease the inbreeding coefficient $\left(F_{\mathrm{IS}}\right)$; whereas strong winds, massive regional seed rains, and low rates of seed capturing likely reduce the SGS within $T$. recurvata populations (Fig. S2). The cross-validation showed significant correlations between real and estimated values of each parameter $(p<0.01)$. Such analysis indicated wind speed and capture probability as, respectively the most and the least accurately predicted parameters (Fig. S3). The $\mathrm{ABC}$ framework ('Approximate Bayesian Computatio ${ }^{30}$ ) successfully constricted the prior distribution of the parameters. The posterior range of these parameters, as estimated by the $\mathrm{ABC}$ (Table 1) were, therefore, used to perform the subsequent simulations (Fig. 3E).

Time and density simulations. We divided the temporal patterns of individual abundance obtained through simulations of the spreading of $T$. recurvata populations in the empirical static landscape (hereafter referred to as time simulations) into three distinct phases, here referred to as Lag (ca. 0 to 10 years), Log (ca. 10 to 25 years), and Stationary (higher than 25 years) phases (Figs. 4A,B and S5). During the Lag phase, the simulations showed that individuals' abundance was maintained at very low levels, while the MLL abundance grows at a linear rate up to ca. 65 MLLs, at the end of the Log phase (Figs. 4A, S5). Up to the half of the Lag phase, when the first few individuals start to clonally grow (i.e., emit new ramets) and reproduce, most of the calculated genetic statistics 


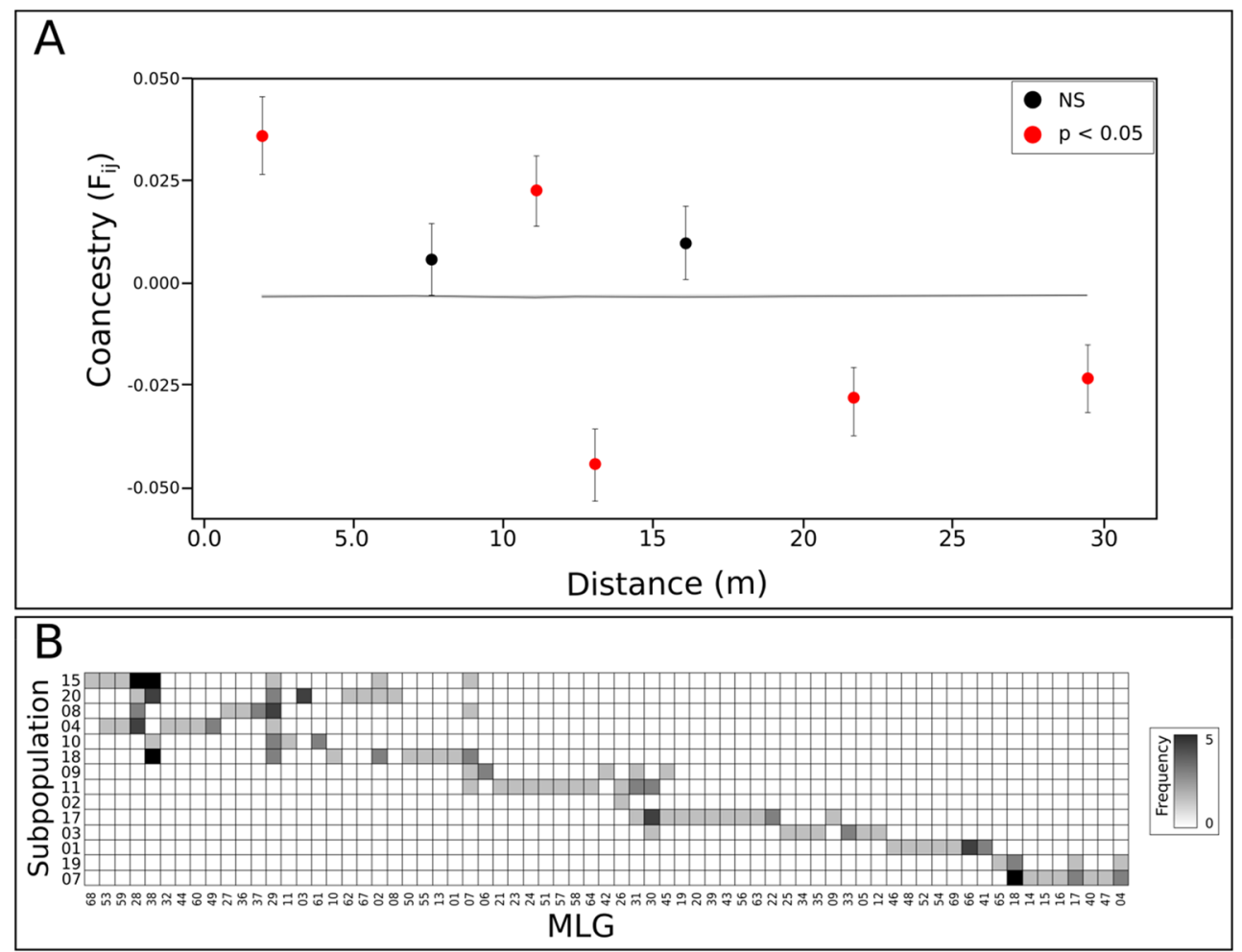

Figure 2. Spatial genetic structure of the empirical Tillandsia recurvata population. (A) correlogram from spatial autocorrelation analysis using the correlation coefficient $\mathrm{Fij}^{59}$ and seven distance classes. The line and the narrow gray area around it represent the expected kinship and 95\% confidence intervals of the null hypothesis with no spatial genetic structuring. Black lines around each average $\mathrm{F}_{\mathrm{ij}}$ value represent their standard errors. (B) Adjacency matrix showing the occurrence of each genotype (MLG) of Tillandsia recurvata (columns) on subpopulations corresponding to each sampled tree (rows). Grey gradient colors represent the frequency of each genotype per subpopulation.

resulted in unstable patterns. Following this initial period, our simulations showed that the increase in the proportion of clones as well as in the aggregation of genotypes from the same MLL within each subpopulation lead the $T$. recurvata population to reach its strongest spatial genetic structuring (SGS), as evidenced by the highest values of $F_{\mathrm{ST}}$ and $\mathrm{S}_{\mathrm{P}}$ (up to ca. 0.35 and 0.01 , respectively), and the lowest mean number of alleles per locus and subpopulation (A; ca. 16) and expected heterozygosity $\left(\mathrm{H}_{\mathrm{E}}\right.$; ca. 0.53$)$. The simulations followed to the Log phase as individuals from the same MLL (commonly with the same genotype) started to disperse seeds to other trees, leading to a boom in individuals abundance and a subpopulation differentiation decay (Fig. 4B). At this phase, the individual abundance rapidly multiplied, mostly by clonal growth, reaching a peak of ca. 12,500 individuals (ca. 192 individuals/MLL; Figs. 4A, S5), increasing the gene flow among subpopulations and leading to a drop in the SGS (i.e. reducing $\mathrm{F}_{\mathrm{ST}}, \mathrm{S}_{\mathrm{P}}$ and MLG and MLL turnover while increasing $A$ and $\mathrm{H}_{\mathrm{E}}$ ). As the individual abundance saturated, at the Stationary phase, all measured variables from simulated genetic data suffered only small variations (Fig. 4B).

From the simulations with distinct tree densities (hereafter referred to as density simulations), we highlighted four key values of tree density in ascending order (see D1 to D4 in Figs. 4C,D, S5) that denote turning points in the individual abundance and SGS of T. recurvata populations. Landscapes with ca. 20 trees/ha (D1) showed the lowest individual abundance, $\mathrm{A}$, and $\mathrm{H}_{\mathrm{E}}$, and the strongest SGS (i.e. the highest $F_{\mathrm{ST}}$, Sp, and MLG- and MLLturnover). Conversely, landscapes with ca. 190 trees/ha (D2) and 275 trees/ha (D3) showed, respectively, the lowest SGS and the highest individual abundance (ca. 550,000 individuals from 220 MLLs). Finally, landscapes with increasing tree densities from 275 (D3) to 375 trees/ha (D4) tended to gradually hold fewer individuals and MLLs as long as the SGS enhances.

Dynamic simulations. From the simulations with dynamic landscapes (i.e. allowing tree growth, regeneration, self-thinning), we observed that removing up to $90 \%$ of the trees from a high-tree density landscape led to $80 \%$ less ground coverage, while the addition of new trees to lower-tree density landscapes led to smaller changes (ca. $10 \%$ ) in the ground cover (see shadowed areas in Fig. 5). Our model showed that deforestation resulted in the loss of up to 200,000 individuals and 120 MLLs of T. recurvata populations (Fig. 5C,D) but to smaller changes in terms of genetic diversity and structure (i.e. A and $F_{\mathrm{ST}}$; Fig. 5E,F). The further effects of tree growth, regeneration, and self-thinning, in turn, unfolded in the convergence of all simulated scenarios to tree densities of ca. 180 


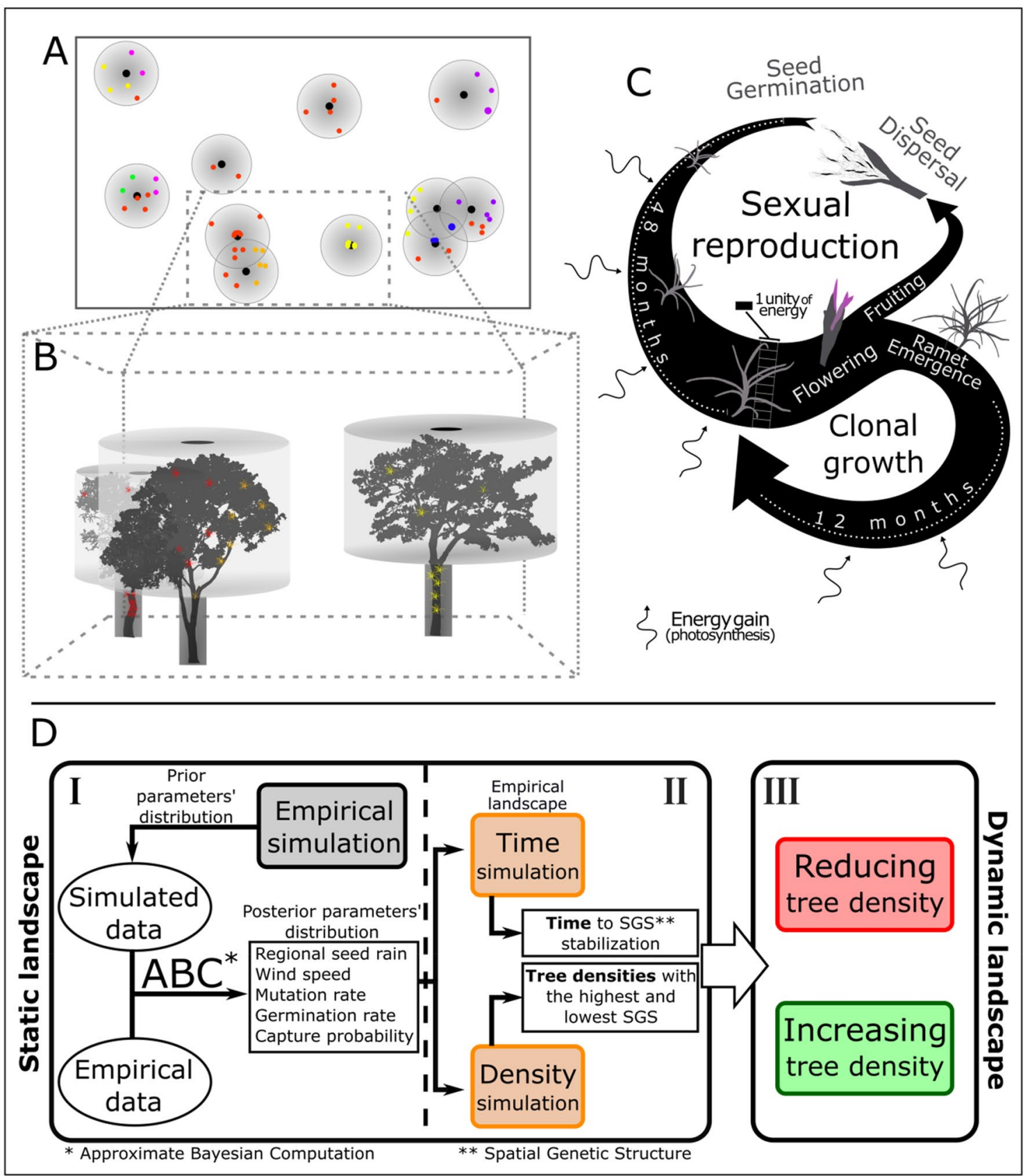

Figure 3. Schematic representations of the TRec model that simulates the Tillandsia recurvata spreading in a 0.40 ha landscape. (A) is a landscape representation of the model implemented in NetLogo. Points with distinct colors represent T. recurvata individuals of distinct genetic lineages (MLLs). Larger circles with a gradient gray color and concentric smaller black circles represent the crowns and trunks of distinct trees. (B) shows a 3D representation of a cut area of the landscape in (A). (C) shows a summarized representation the life cycle of $T$. recurvata. The arrow width represents the amount of energy accumulated in each life stage. Dotted lines indicate the time for maturity and reproduction. Small rectangles indicate the minimal units of energy for individual reproduction. The amount of energy accumulated is variable according to the local shading rate, affecting both sexual reproduction and clonal growth. For the TRec model, the T. recurvata lifespan is 72 months. (D) shows a flowchart diagram with the steps to adjust the TRec parameters (in white squares) to run distinct simulations (in colored rounded squares) aiming to analyze the distinct aspects of the effect of tree density on the spatial genetic structure (SGS) of T. recurvata populations. I: delimits the main processes for parameters estimation based on the empirical data; II: delimits the main process for estimation of time for SGS stabilization and tree densities in which the highest and lowest SGS are achieved; III: delimits the main processes to analyze the SGS variation considering dynamic landscapes. 


\begin{tabular}{|l|l|l|l|l|l|}
\hline Parameter & Definition & Prior range (min-max) & Prior distribution & Posterior range (CI 95\%) & References \\
\hline Regional seed rain & $\begin{array}{l}\text { Number of seeds that reach the land- } \\
\text { scape at each reproductive season }\end{array}$ & $100-500$ seeds/year & Uniform & $88-264$ & Previous simulations tests \\
\hline Wind speed & The magnitude of seed dispersal & $1-20$ units & Uniform & $13.95-21.28$ & Previous simulations tests \\
\hline Mutation rate & Average SSR mutation-rate & $10^{-6}-10^{-2}\left(\mathrm{mean}=10^{-4} ; \mathrm{sd}=10^{-3.5}\right)$ & Normal & $10^{-5.28}-10^{-4.07}$ & $61-63$ \\
\hline Germination rate & Seed germination rate & $0.0083-0.30$ & Uniform & $0.162-0.297$ & 48,64 \\
\hline Capture probability & $\begin{array}{l}\text { The probability of seeds be captured in } \\
\text { the canopy }\end{array}$ & $0.01-0.30$ & Uniform & $0.150-0.296$ & 65 \\
\hline
\end{tabular}

Table 1. TRec model parameters of Tillandsia recurvata populations. Prior ranges are based on literature or previous simulation tests, while posterior ranges are based on the ABC framework. ${ }^{\star}$ Each wind speed unit is multiplied by five to refer to the amount of 'landscape patches' in the model the seeds can fly freely at each time step of the model.
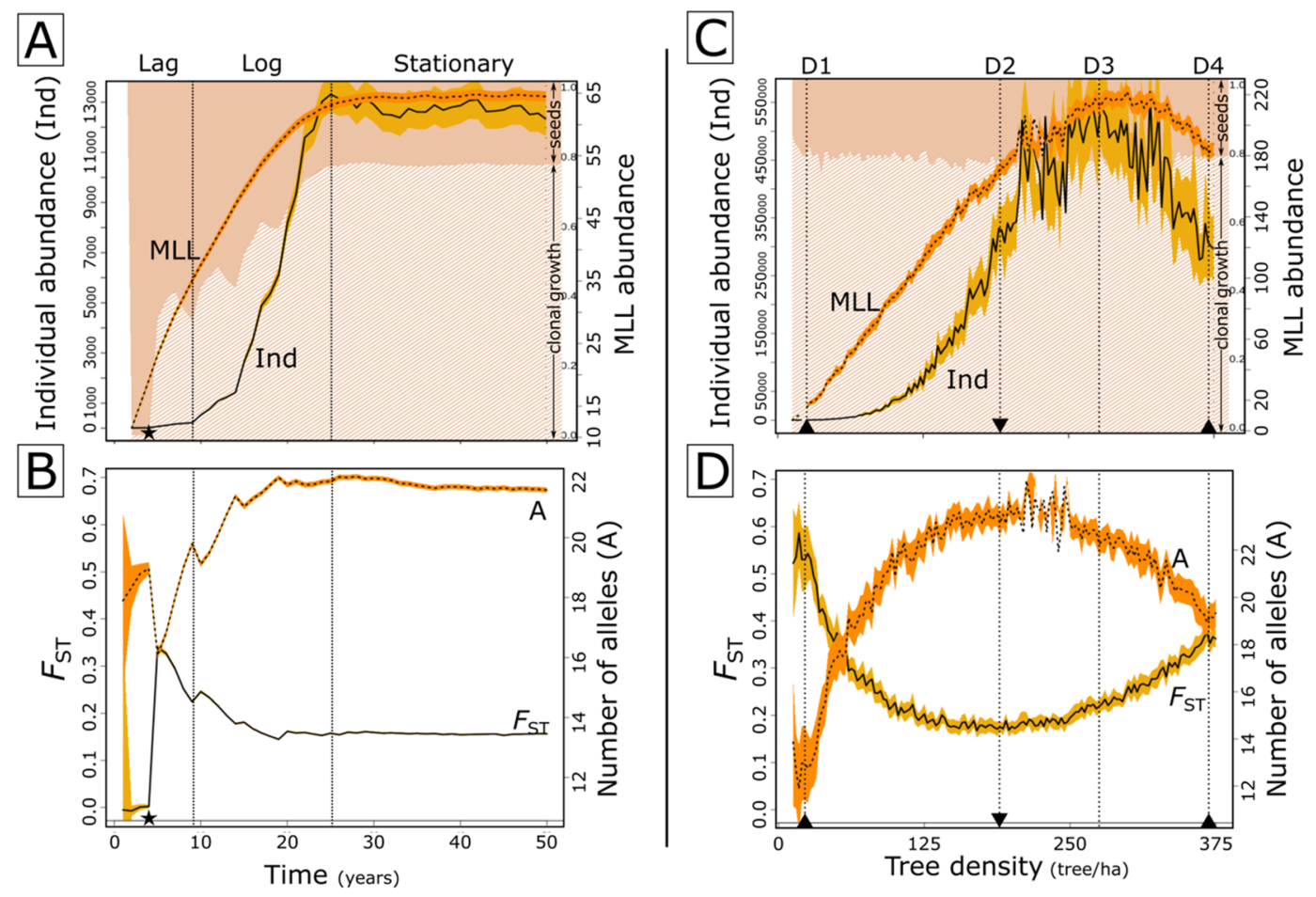

Figure 4. Patterns obtained from multiple simulations of the spreading of Tillandsia recurvata populations in the empirical static landscape (see Fig. 1) over 50 years (A, B), and in static landscapes with varying tree densities after 20 years of simulations (C, D). (A) and (C) show the abundance of individuals (solid line) and multi-locus lineages (MLLs, dotted line), as well as the clonal-growth proportion (lighter background). (B) and (D) show the pairwise subpopulation differentiation $\left(F_{\mathrm{ST}}\right.$, solid line) and the average number of alleles per subpopulation (dotted line). Yellowed areas around lines represent the $95 \%$ confidence intervals of each variable in a total of 2500 (A, B) and 7000 (C, D) simulations. In (A) and (B), "Lag", "Log", and "Stationary" phases are delimited by vertical lines. In (C) and (D), vertical lines highlight turning points in the individual abundance and $F_{\mathrm{ST}}$ of T. recurvata populations (D1-D4). Stars highlight the 4th simulated year, when the first arriving seeds reach maturity. Down and up arrowheads highlight tree densities with the lowest and highest $F_{\mathrm{ST}}$, respectively.

trees/ha (Fig. 5A). The simulations also showed a tendency of convergence in the proportion of ground cover (ca. 100\%; Fig. 5B) and MLL abundance of T. recurvata populations (ca. 140 MLLs; Fig. 5D) among such distinct scenarios after the first 60 years following the tree density changes. Populations from deforested and reforested landscapes, however, showed distinct patterns of individual abundance (Fig. 5C). While T. recurvata populations from deforested landscapes increased up to ca. 600,000 individuals between the 30th and the 60th year, populations from reforested landscapes shrank up to $35 \%$ of individuals from the 45 th year onwards. The differences in the number of individuals per MLL (Fig. S6) resulted in reducing SGS over time in populations from deforested landscapes and an increasing SGS over time in populations from reforested landscapes (Fig. 5E). Compared to the low and moderate tree density changes, the scenario with a massive loss of $90 \%$ of trees led to a particularly weaker increment of individuals (Fig. 5C). Such increment resulted in individual abundances closer to that observed in reforested landscapes, but with a lower mean number of alleles per subpopulation (A; Fig. 5F). 


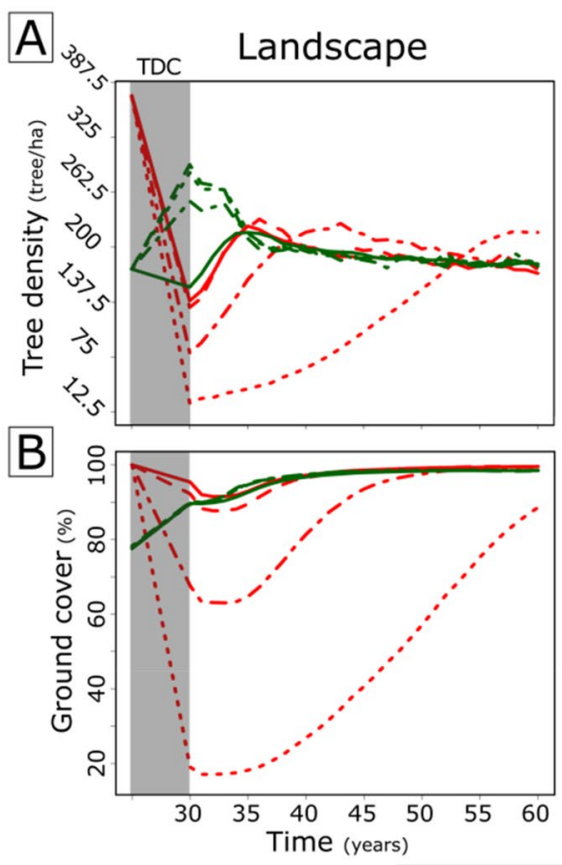

\begin{tabular}{c} 
Prior tree density \\
High (375 trees/ha) \\
\hline Low (175 trees/ha)
\end{tabular}

D
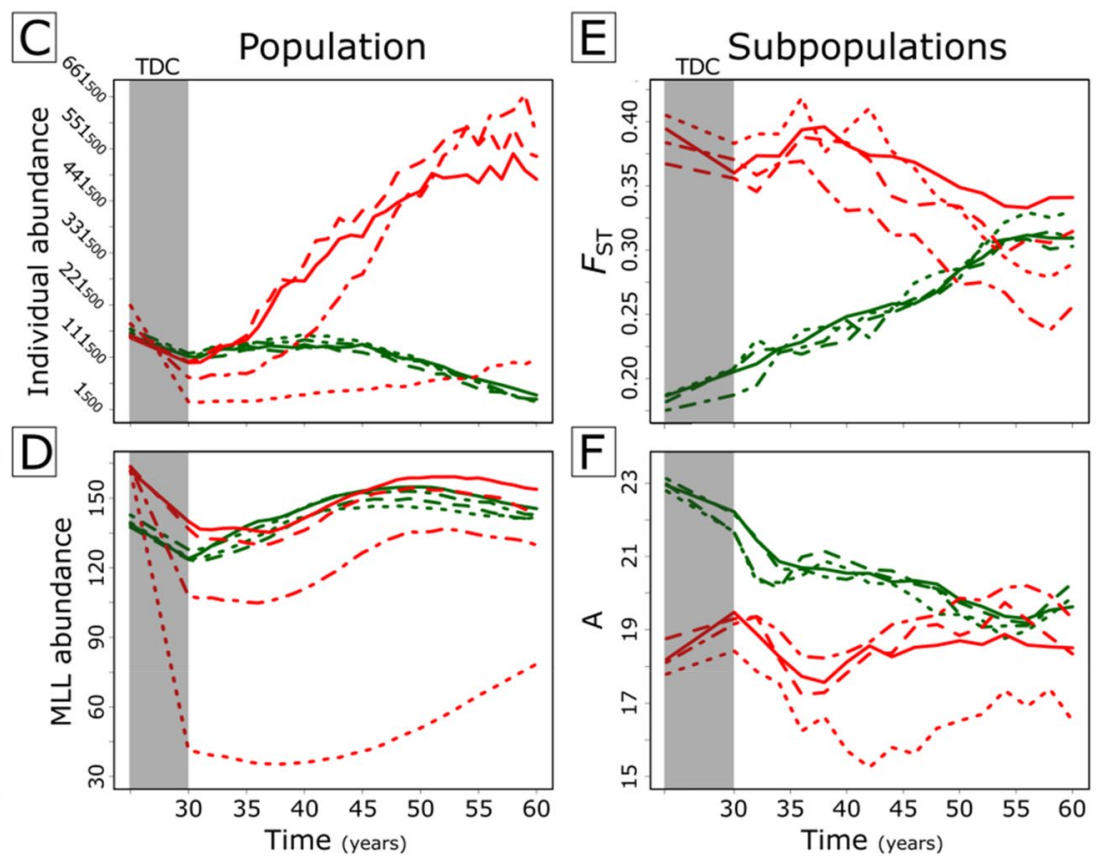

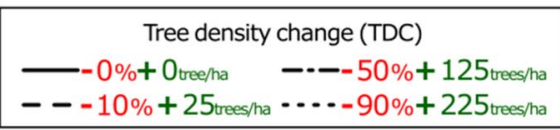

Figure 5. Temporal patterns obtained from multiple simulations of the spreading of Tillandsia recurvata populations in dynamic landscapes (emulating tree growth, regeneration, and self-thinning of natural forests) with prior high and low tree densities after abrupt reductions (lines in red) or increments (lines in green) in tree densities (shaded areas). The first 30 simulated years, not shown here, correspond to the simulations in static landscapes presenting the lowest and highest $\mathrm{F}_{\mathrm{ST}}$ (considering high tree density conditions) showed in Fig. 4C,D. From the first to the last column, the figures show 30 -years of posterior temporal variation in landscapes' tree density (A) and ground cover (i.e. the relative number of simulated landscape patches not covered by tree trunks or crowns; (B); in the T. recurvata's population abundance of individuals $(\mathbf{C})$ and multi-locus lineages (MLLs; $(\mathbf{D})$; and in subpopulation' differentiation $\left(F_{\mathrm{ST}} ; \mathbf{E}\right)$ and the average number of alleles $(\mathbf{A} ; \mathbf{F})$. Lines represent the averages of each represented variable in 2000 simulations. Solid, dashed, dotted-dashed, and dotted lines represent, respectively, absent, low, intermediate, and high anthropogenic changes in tree density (TDC).

\section{Discussion}

In this study, we integrated empirical and simulated genetic data to provide insights into the spreading of the epiphytic weed Tillandsia recurvata, which is widespread into human-transformed landscapes. Our empirical data reveals a relatively high spatial genetic structure (SGS; i.e. low gene flow) in a small landscape (c.a. 0.2 ha) with low tree density and opportunistically colonized by a massive population of this species. Each tree in this system functions as habitat units, forming distinct subpopulations of T. recurvata that group specific sets of multi-locus genotypes (MLG). The data simulated by our TRec model indicate that the highest levels of SGS in T. recurvata occur at the very beginning of the colonization process and under extremely low or high tree densities. As expected, lower SGS occur at landscapes in which seed dispersal is limited neither by long distances among spaced trees nor by the low carry capacity of wind among dense canopies. The TRec model also shows that deforestation is a turning point for the opportunistic thriving of T. recurvata populations. Our results contribute to the understanding of the dynamics of species invasiveness and landscape invasibility and also on the consequences of human-induced changes for the spreading of opportunistic species, as we discuss below.

The patchy distribution of a $T$. recurvata population. Our empirical study in an anthropic landscape showed a relatively high to moderate SGS for a population of T. recurvata at a fine-scale (ca. $2000 \mathrm{~m}^{2}$ ), as indicated by the significant $S_{p}$ statistics and high subpopulation differentiation. Such SGS likely arises as an outcome of the breeding system and life form of T. recurvata, which limits local gene flow, resulting in a significant isolation-by-distance, persistence of private alleles in six out of 14 studied subpopulations, as well as high MLGs turnover. Indeed, fine-scale SGS often results from limited gene flow ${ }^{66,67}$, and other studies have reported similar genetic patterns for plants with, self-reproduction ${ }^{68,69}$, clonal growth ${ }^{69,70}$, epiphytic habit ${ }^{51,52,71}$, fast-growth ${ }^{72,73}$, and high-density populations ${ }^{66,74}$. Our results indicate, therefore, that specific habits and breeding systems can foster the structuring of populations, even for opportunistic and widespread plants.

The few MLGs shared among subpopulations indicate that the T. recurvata spreading is gradually conducted by several multi-locus lineages (MLLs) following a phalanx pattern, rather than by a single leading $\mathrm{MLL}^{40}$. The relatively low $S_{P}$ observed for a selfing species ${ }^{66}$, in turn, seems to be related to its dense populations ${ }^{66,74}$. 
These results suggest that multiple and dense sources of T. recurvata propagules from the surrounding areas are responsible for the massively spreading over the studied landscape. Under such conditions, self-reproduction and clonal growth ${ }^{46-48}$ may lead to a partial, and perhaps transitory, isolation among subpopulations ${ }^{67}$. Beyond the effect of the breeding system and life form, the relatively high SGS of T. recurvata population may also result from founder events on each host tree ${ }^{40,67}$. Nevertheless, the genetic drift resulting from consecutive founder events, as well as the increasing number of seeds released from large subpopulations, may intensify the metapopulation dynamics of successive local extinctions and recolonizations, reducing the genetic structure of the population over time $\mathrm{e}^{12,13,27}$.

Temporal patterns in the opportunistic spreading of T. recurvata. The temporal dynamics of the simulated $T$. recurvata population resembles the diffusion models of weedy species invasion in newly disturbed landscapes, with sequential Lag, Log, and Stationary phases ${ }^{75}$. During the Lag phase (up to the 10th year), only a few T. recurvata individuals successfully establish in the landscape, despite the constant input of new genetic lineages (MLLs) per reproductive season. At this stage, as clonal growth continues and the proportion of clones increases, leading to aggregated individuals holding the same genotypes within each subpopulation, the population reaches the highest genetic structure. The reproduction start of such large groups of genetically related individuals leads to a boom in the overall individual abundance, part of the newly produced seeds is exchanged among subpopulations and causes a gradual decrease in the genetic structure, as observed in other empirical studies ${ }^{47,66}$. It is notorious, at this point, the impact of clonal-growth in T. recurvata spreading, overcoming the demographic stochasticity and the Allee effect ${ }^{10,76,77}$, and leading the population to the following Log phase (10th to 25 th year).

The rapid increase in individual abundance during the Log phase drives the interchange of seeds, and therefore MLGs, among subpopulations, leading to an overall reduction in subpopulation differentiation and genetic structuring. However, the saturation of the static system limits the establishment of a higher number of individuals and MLLs, maintaining all calculated statistics at a steady level after the 25th year (the Stationary phase). Such increment and further stabilization of gene flow at relatively high levels indicate a potential role of T. recurvata populations as a source of seeds for supporting the species spread into newly disturbed areas after ca. 25 years of colonization. Notwithstanding the specific characteristics of each species, this temporal pattern is typical for opportunistic organisms growing under optimal conditions ${ }^{75}$. As observed for T. recurvata, a fast increase and stabilization in the individual abundance of populations and communities are expected for static systems ${ }^{78,79}$. However, given their xerophytic preference, distinct patterns in the spreading of T. recurvata populations can came across in landscapes with varying tree densities, as we see in the following section.

Effects of tree density on T. recurvata spreading. Our model indicates that the highest gene flow (i.e. the lowest SGS) among T. recurvata subpopulations occur in landscapes with ca. 190 trees/ha, which likely represents the ideal condition for the species spreading. Landscapes with fewer trees tend to harbor fewer individuals of T. recurvata, from which the seeds have to cross longer distances that likely prevent gene flow. On the other hand, landscapes with more than 190 trees/ha counterbalance the effect of increasing habitat amount for epiphytic hosting ${ }^{80,81}$ with the intensification of shading and wind friction for seed dispersal ${ }^{82-84}$. Indeed, as we observed here, studies implementing IBM approaches for distinct biological systems have shown that the abundance and genetic structuring of populations result from the interplay between habitat amount and resistance to gene flow across landscapes ${ }^{57,58}$. For T. recurvata, unlike other epiphytes ${ }^{80,85}$, the heavy overlapping of tree crowns in dense forests likely reduces the species' fitness, resulting in small, transient, and isolated populations constrained to the driest and upper canopy layers ${ }^{37,80,86,87}$. Further studies incorporating the genetic component of fitness into the models can give more insights into the colonization process and the invasiveness of this opportunistic species. The increasing number of genome-wide markers generated by high-throughput sequencing, as well as the constant development of computational methods, will also allow future investigation on the relative importance of natural selection on the genetic structure of such species.

Changing landscapes and opportunistic spreading of T. recurvata. The combined effect of abrupt reductions in tree density and natural self-thinning have enabled the opportunistic thriving of T. recurvata populations in formerly densely forested landscapes. Indeed, studies have suggested that conditions found in dense forests typically prevent the colonization and development of this species, given the limited carrying capacity of wind for seed dispersal ${ }^{80-84}$. Using our model approach, we observed an overgrowth of $T$. recurvata populations in recovering landscapes that suffered low to moderate tree removal, with a significant increase in gene flow. The massive deforestation (i.e. $90 \%$ of tree removal), in contrast, reduces drastically the number of available host trees, leading, as expected, to smaller populations of T. recurvata and increasing gene flow among subpopulations as the forest regenerates.

Reforestation, in turn, slowly leads T. recurvata populations in the opposite direction. In our model, the presence of only $20 \%$ of uncovered ground (i.e. spaces uncovered by tree trunks or crowns and, thus, able to receive new trees) under lower-tree densities constrained the active increment of trees, reducing the differences among the distinct levels of reforestation. Despite the milder effects in comparison to deforestation, the active increase in tree density and the continuous growth of the former trees likely reduce the abundance of T. recurvata and the gene flow among subpopulations. The larger and older trees in reforested landscapes, compared to the smaller and younger trees in landscapes following deforestation, could play a major role in increasing shading and reducing the carrying capacity of wind for seed dispersal. Therefore, our results indicate that the control of T. recurvata spreading depends not only on the tree density of landscapes but also on the stage of forest recovery. 
In other words, the positive effects of controlling weeds with posterior reforestation, besides costly, can be much more time-consuming than just avoiding deforestation.

\section{Conclusion}

Opportunistic species provide an excellent system to examine the process of successful colonization in novel environments ${ }^{7}$. Here, we demonstrate that 'weedy' traits, such as selfing and clonal growth ${ }^{13,18,19}$, may lead populations to distinct outcomes depending on the landscape conditions. In some landscapes, such traits undermine gene flow and genetic diversity, potentially increasing inbreeding in populations ${ }^{18-22}$, but under ideal conditions, they can also mitigate the Allee effect by assuring the genet survival, seed dispersal, and genetic transmission ${ }^{14-16}$. Our study also shows that anthropogenic deforestation is the turning point to increase the invasibility of landscapes, enabling the rapid thrive and spreading of $T$. recurvata especially onto recovering landscapes, where smaller trees produce reduced cover on once heavily shaded ground by larger trees. As have been shown by other studies ${ }^{88-90}$, our findings reveal that reforestation has milder and slower effects on mitigating the impact of massive tree removal on the spreading of opportunistic species, highlighting the importance of maintaining forests instead of investing in restorations. On the other hand, landscape features determined by shading, as well as growth, reproduction, and competitiveness among trees likely lead to alternative outcomes for epiphytes. Testing the impact of distinct environmental conditions (e.g. soil, climate, etc.) on the assembling of tree groups would be a wise step toward a more global understanding of invasion ecology.

\section{Methods}

Empirical genetic data. The empirical study took place in a human-transformed landscape of ca. 0.2 ha in southwest Brazil $\left(-21.244289^{\circ} \mathrm{S},-48.300486^{\circ} \mathrm{W}\right)$ composed of a grove of 20 cultivated Handroanthus spp. (Bignoniaceae) of similar ages (ca. 20 years) apart from each other from 2.5 to $47.5 \mathrm{~m}$ and surrounded by a grassland matrix (ca. 100 tree/ha; Fig. 1). As it is common in many human-transformed landscapes, the empirical landscape results from the complete deforestation followed by a landscaping procedure that prevents nonplanted specimens to grow amongst introduced trees on which a massive T. recurvata population has colonized.

We sampled a total of 224 individuals of T. recurvata growing on 14 neighboring trees (16 individuals per tree; hereafter referred to as "subpopulations") and extracted the total genomic DNA from leaf samples according to Tel-Zur et al. ${ }^{91}$. The collection of plant material complied with national guidelines. Permits to collect in conservation units were granted by COTEC (Technical and Scientific Committee of the Forestry Institute, São Paulo, Brazil; permission number 006.221/2014) and SISBIO (Biodiversity Information and Authorization System, Brazil, permission number 44443-1). We characterized the multi-locus genotype (MLG) of each individual using seven microsatellite loci designed for other species and cross-amplified them as described by Chaves et al. ${ }^{92}$. We avoided sampling clones by collecting individuals at distinct branches of each host tree. Indeed, clonal individuals of T. recurvata (i.e., ramets) can be easily distinguished because they are formed on leaf axils and remain attached, conferring the typical "ball" shape of the species ${ }^{38}$.

To describe the genetic diversity within each $T$. recurvata subpopulation, we calculated the number of alleles (A), allelic richness $\left(A_{R}\right)$, the private number of alleles $\left(A_{P}\right)$, expected $\left(H_{E}\right)$ and observed heterozygosity $\left(H_{O}\right)$, and inbreeding coefficient $\left(F_{\mathrm{IS}}\right)$ and tested for departures from Hardy-Weinberg equilibrium using the R statistical package diveRsity ${ }^{93}$. Furthermore, we tested whether subpopulations were isolated-by-distance using a Mantel test with Slatkin's linearized $F_{\mathrm{ST}}\left(F_{\mathrm{ST}} /\left(1-F_{\mathrm{ST}}\right)\right)^{94}$, Nei's ${ }^{95}$, Edward's ${ }^{96}$, and Reynold's ${ }^{97}$ pairwise genetic distances and the logarithm of geographical distance using the $\mathrm{R}$ statistical packages poppr ${ }^{98}$ and pegas ${ }^{99}$. We also measured pairwise subpopulation differentiation $\left(F_{\mathrm{ST}}\right)$ and tested the hierarchical partition of genetic variance among and within sampled subpopulations by performing an analysis of molecular variance (AMOVA ${ }^{100}$ ), using the R statistical package poppr ${ }^{98}$.

To investigate the spatial genetic structure (SGS) within the T. recurvata population sampled, we tested whether the distance among T. recurvata individuals (disregarding tree crowns) affects their relatedness. For this, we estimated the kinship coefficient $\left(\mathrm{F}_{\mathrm{ij}}{ }^{101}\right)$ between all pairs of individuals sampled within seven distance classes, each comprising the same number of pairs, using the R package RClone ${ }^{102}$. To quantify the SGS under this approach, we calculated the $S_{p}$ statistics (i.e. the ratio between the kinship decay by increasing geographic distances and the mean kinship within the first interval distance $\left.{ }^{66}\right)$ and tested the statistical significance of the mean kinship coefficient values in each distance class (confidence interval: $95 \%$ ) by randomly shuffle $(1000 \times)$ individual locations ${ }^{66}$. We also quantified the partitioning of the genetic composition of the whole population by calculating the turnover of alleles and multi-locus genotypes among subpopulations (MLG ${ }^{103,104}$ ), using the $\mathrm{R}$ statistical package vegetarian ${ }^{105}$.

The TRec model. We implemented the TRec model in NetLogo 6.0.1 ${ }^{106}$ and outlined it following the ODD (Overview, Design concepts, Details) protocol formulated by Grimm et al. ${ }^{107,108}$ (see Appendix S1 in Supporting Information). The model simulates a landscape composed of multiple $0.01 \mathrm{~m}^{2}$ patches of soil with scattered trees that are colonized by multiple seeds of T. recurvata with distinct MLGs (based on empirical alleles). Such seeds annually reach the landscape from outside (hereafter referred to as 'regional seeds') by wind dispersal and generate mature individuals that reproduce by self-fertilization and grow by producing new ramets (clonal growth) on trees within the landscape (Fig. 3). The wind speed is quantified in correspondence with the total distance (in units of 'landscape patches') in which seeds are carried at each time step. The colonization dynamics of the model is primarily based on the 'energy budget' of T. recurvata, which quantifies, under a simplified manner, the amount of energy each individual takes up by photosynthesis and expends during its life cycle through metabolism, growth, and reproduction (including seed dispersal and clonal growth), depending on the shading rate and competition of its attachment site (Fig. 3). The energy budget approach is based on the Dynamic Energy Budget 
theory of Kooijman ${ }^{109}$ and has been adopted in IBMs to generally describe how individuals acquire and expend energy with simple and sufficient realism ${ }^{110-112}$. Therefore, at each time step, the TRec model update the amount of energy of every individual simulated. The survival as well as the capacity of each $T$. recurvata individual to grow and reproduce depends on the amount of energy stocked up until the reproductive season (Fig. 3). In the TRec model, mature individuals (i.e. older than 48 months) with a energy budget with at least 10 units will grow clonally and produce and disperse new seeds in the reproductive season (Fig. 3). T. recurvata individuals can reproduce only once and die when they reach their lifespan (72 months) or whether they maintain a net-zero gain of energy, with expenses surpassing gain (i.e. energy equals to 0 units). For the TRec model, we assume that each seed that successfully develops and thrives in the landscape forms a multi-locus lineage (MLL) of multiple descendants, which can be traced back to the ancestor. Each new seed produced within the landscape can also be wind-dispersed by chance from the mother to other trees, but new ramets are always attached to the same host tree. Each MLL often groups multiple MLGs due to heterozygous loci (according to the heterozygosity observed in the empirical study). Another source of genetic variation within MLLs is simulated by a varying mutation rate (from $10^{-2}$ to $10^{-6}$ ) that simulates DNA replication slippages of SSR loci.

The simulation process using the TRec model was comprised of three subsequent phases (Fig. 3E): (I) parameters estimation based on the empirical data using approximate bayesian computation (ABC); (II) estimation of time for SGS stabilization and densities in which the highest and lowest SGS is achieved; and (III) analysis of the effect of gradual and abrupt changes of tree densities in a dynamic landscape. For phase I (Fig. 3E), we simulated 250,000 microsatellite datasets generated by random combinations of five parameters with a priori estimates according to general assumptions or previous knowledge on the species (see Table 1). We then performed a Global Sensitivity Analysis to test whether summary statistics-i.e., the mean number of alleles (K), mean range of allele size $(\mathrm{R})$, mean expected heterozygosity $\left(\mathrm{H}_{\mathrm{E}}\right)$, mean inbreeding coefficient $\left(F_{\mathrm{IS}}\right)$, global subpopulation differentiation $\left(F_{\mathrm{ST}}\right)$, and mean modified Garza-Williamson statistic ${ }^{113,114}$ _as well as T. recurvata abundance and the total number of MLL, are differently affected by the variation of each parameter. To improve the TRec model accuracy, we estimated posterior distributions of the model parameters in an ABC framework ('Approximate Bayesian Computation ${ }^{60}$ ). We employed the network algorithm implemented in the 'abc' R package ${ }^{115}$ to estimate such distribution based on $0.1 \%$ retained simulations that most resembled the empirical SSR data according to the six above-mentioned summary statistics (i.e. $\mathrm{K}, \mathrm{R}, \mathrm{H}_{\mathrm{E}}, \mathrm{F}_{\mathrm{IS}}, \mathrm{F}_{\mathrm{ST}}$, and $\mathrm{NGW}$ ).

Time and density simulations. For the second phase of the simulation process (see Fig. 3E), we used the estimated posterior range of each Trec parameter (see Table 1) to estimate the time needed for the stabilization of the spatial genetic structure (SGS) of T. recurvata populations (hereafter referred to as 'time simulation') and the tree densities values for which the lowest and highest SGS values are achieved (hereafter referred to as 'density simulation'). To reduce the bias effect inherent to dynamic landscapes (e.g. with growing and falling trees), we performed both time and density simulations in static landscapes. We performed 2500-time simulations that emulate 50 years of spreading of T. recurvata individuals on the empirical landscape representation (Fig. 1), and 5000 density simulations of T. recurvata populations in ca. 0.40 hectares landscapes with five to 150 trees (maximum amount of trees that occupy the landscape) with random heights and same crown sizes. Yearly (for the time simulations) and after 30 years (for the density simulations), we recorded the individual and MLL abundances, as well as the MLG, MLL, and ramets' origins (from clonal growth or sexual reproduction; hereafter referred to as 'clones' and 'seeds' individuals) of up to 15 random T. recurvata individuals established on each host tree representation of the empirical study (for the time simulations) or on up to 15 random trees for density simulations (for the density simulations). Based on the MLGs of each simulation, we calculated the average number of alleles (A), the expected heterozygosity $\left(\mathrm{H}_{\mathrm{E}}\right)$, the inbreeding coefficient $\left(F_{\mathrm{IS}}\right)$, and the global subpopulation differentiation $\left(F_{\mathrm{ST}}\right)$, using the ARLSUMSTAT console version of Arlequin 3.1; the MLG and MLL turnovers among subpopulations $\left(\mathrm{T} / \mathrm{O}_{\mathrm{MLG}}\right.$ and $\left.\mathrm{T} / \mathrm{O}_{\mathrm{MLL}}\right)$, using the $\mathrm{R}$ package vegetarian ${ }^{104,105}$; and the $\mathrm{S}_{\mathrm{p}}$ statistics considering seven distance classes as in the empirical study ${ }^{66}$ using the R package RClone ${ }^{102}$.

Dynamic simulations. To emulate the effect of human-induced changes of tree density on the SGS of T. recurvata populations (the phase III in Fig. 3E), the hereafter referred to as 'dynamic simulations' add distinct levels of changes that actively reduce or increase tree density mimicking either deforestation or reforestation. For this, the dynamic simulations firstly simulated 30 years (when the SGS stabilizes) of T. recurvata spreading over static landscapes with low (175 trees/ha; when T. recurvata populations showed the lowest SGS) and high tree densities (375 trees/ha; when $T$. recurvata populations showed the highest SGS in landscapes with high tree densities). After these first 30 years, the model emulates distinct levels of anthropogenic reductions $(0,10,50$, or $90 \%$ of the prior tree density) and increments in tree density (by adding 0, 25, 125, or 225 trees/ha) in high and low tree density landscapes, respectively. Thereafter, we yearly calculated individual and MLL abundances, A, $\mathrm{H}_{\mathrm{E}}$, and $F_{\mathrm{ST}}$ using the ARLSUMSTAT console version of Arlequin 3.1 over 30 additional years in landscapes allowing tree density variation as the result of tree-growth (an average DBH increase of $0.13 \mathrm{~cm} /$ year $^{116}$ ), self-thinning (according to the Yoda's law), and natural regeneration (a fixed rate at 15\%; for further information, please see the ODD in the Supporting Information). Here, as in the time and density simulations, we also included the estimated posterior range of the IBM parameters (see Table 1).

\section{Data availability}

The microsatellite data generated in this study, as well as all scripts used in the simulations, are stored at the FigShare repository [https://doi.org/10.6084/m9.figshare.12797846]. 
Received: 25 February 2021; Accepted: 27 September 2021

Published online: 14 October 2021

\section{References}

1. de Wet, J. M. J. \& Harlan, J. R. Weeds and domesticates: Evolution in the man-made habitat. Econ. Bot. 29(2), 99-108. https:// doi.org/10.1007/BF02863309 (1975).

2. Ceballos, G. et al. Accelerated modern human-Induced species losses: Entering the sixth mass extinction. Sci. Adv. 1(June), 1-6. https://doi.org/10.1126/sciadv.1400253 (2015).

3. Wilcove, D. S. Nest predation in forest tracts and the decline of migratory songbirds. Ecology 66(4), 1211-1214 (1985).

4. Airoldi, L. \& Bulleri, F. Anthropogenic disturbance can determine the magnitude of opportunistic species responses on marine urban infrastructures. PLoS ONE https://doi.org/10.1371/journal.pone.0022985 (2011).

5. Baker, H. G. The evolution of weeds. Annu. Rev. Ecol. Syst. 5, 1-24. https://doi.org/10.2307/2096877 (1974).

6. Richardson, D. M. et al. Naturalization and invasion of alien plants: Concepts and definitions. Divers. Distrib. 6, 93-107 (2008).

7. van Etten, M. L., Conner, J. K., Chang, S. M. \& Baucom, R. S. Not all weeds are created equal: A database approach uncovers differences in the sexual system of native and introduced weeds. Ecol. Evol. 7(8), 2636-2642. https://doi.org/10.1002/ece3.2820 (2017).

8. Booth, B. D. \& Swanton, C. J. Assembly theory applied to weed communities 50th Anniversary-Invited Article Assembly theory applied to weed communities. Weed Sci. 50(3), 2-13. https://doi.org/10.1614/0043-1745(2002)050 (2002).

9. Kuester, A., Conner, J. K., Culley, T. \& Baucom, R. S. How weeds emerge: A taxonomic and trait-based examination using United States data. New Phytol. 202(3), 1055-1068. https://doi.org/10.1111/nph.12698 (2014).

10. van Kleunen, M. et al. The ecology and evolution of alien plants. Annu. Rev. Ecol. Evol. Syst. https://doi.org/10.1146/annurevecolsys-110617-062654 (2018).

11. de Bona, S. et al. Spatio-temporal dynamics of density-dependent dispersal during a population colonisation. Ecol. Lett. 22, 634-644 (2019).

12. Baker, H. G. Self-compatibility and establishment after "long-distance" dispersal. Evolution 9(3), 347. https://doi.org/10.2307/ 2405656 (1955).

13. Razanajatovo, M. et al. Plants capable of selfing are more likely to become naturalized. Nat. Commun. 7, 13313. https://doi.org/ 10.1038/ncomms13313 (2016).

14. Vallejo-Marín, M., Dorken, M. E. \& Barrett, S. C. H. The ecological and evolutionary consequences of clonality for plant mating. Annu. Rev. Ecol. Evol. Syst. 41(1), 193-213. https://doi.org/10.1146/annurev.ecolsys.110308.120258 (2010).

15. Rodger, J. G., Van Kleunen, M. \& Johnson, S. D. Pollinators, mates and Allee effects: The importance of self-pollination for fecundity in an invasive lily. Funct. Ecol. 27(4), 1023-1033. https://doi.org/10.1111/1365-2435.12093 (2013).

16. Barrett, S. C. H. \& Harder, L. D. The ecology of mating and its evolutionary consequences in seed plants. Annu. Rev. Ecol. Evol. Syst. https://doi.org/10.1146/annurev-ecolsys-110316-023021 (2017).

17. Klimeš, L., Klimešová, J., Hendriks, R. \& van Groenendael, J. Clonal plant architecture: A comparative analysis of form and function. In The Ecology and Evolution of Clonal Plants (eds De Kroon, H. \& Van Groenendael, J. M.) 1-29 (Backhuys, 1997).

18. Barrett, S. C. H. Influences of clonality on plant sexual reproduction. Proc. Natl. Acad. Sci. 112(29), 8859-8866. https://doi.org/ 10.1073/pnas.1501712112 (2015).

19. Heywood, J. S. Spatial analysis of genetic variation in plant populations. Annu. Rev. Ecol. Syst. 22, 335-355 (1991).

20. Barrett, S. C. H. Evolution of mating systems: Outcrossing versus selfing. In The Princeton Guide to Evolution (ed. Losos, J. B.) 356-362 (Princeton University Press, 2013).

21. Barrett, S. C. H., Arunkumar, R. \& Wright, S. I. The demography and population genomics of evolutionary transitions to selffertilization in plants. Philos. Trans. R. Soc. B Biol. Sci. 369(1648), 20130344 (2014).

22. Picó, F. X., Quintana-Ascencio, P. F., Mildén, M., Ehrlén, J. \& Pfingsten, I. Modelling the effects of genetics and habitat on the demography of a grassland herb. Basic Appl. Ecol. 10(2), 122-130. https://doi.org/10.1016/j.baae.2008.02.006 (2009).

23. Ellstrand, N. C. \& Roose, M. L. Patterns of genotypic diversity in clonal plant species. Am. J. Bot. 74, 123-131 (1987)

24. Loh, R., Scarano, F. R., Alves-Ferreira, M. \& Salgueiro, F. Implications of clonality to population genetic structure of the nurse species Aechmea nuducaulis (L.) Griseb. (Bromeliaceae). Bot. J. Linn. Soc. 178, 329-341 (2015).

25. Hedrick, P. W. Purging inbreeding depression and the probability of extinction: Full-sib mating. Heredity 73, 363-372. https:// doi.org/10.1038/hdy.1994.183 (1994).

26. Arunkumar, R., Ness, R. W., Wright, S. I. \& Barrett, S. C. H. The evolution of selfing is accompanied by reduced efficacy of selection and purging of deleterious mutations. Genetics 199(3), 817-829. https://doi.org/10.1534/genetics.114.172809 (2015).

27. Pannell, J. R. \& Barrett, S. C. H. Baker's law revisited: Reproductive assurance in a metapopulation. Evolution 52(3), 657-668. https://doi.org/10.2307/2411261 (1998).

28. Hamrick, J. L. \& Trapnell, D. W. Using population genetic analyses to understand seed dispersal patterns. Acta Oecologica 37, 641-649 (2011).

29. Côrtes, M. C. et al. Low plant density enhances gene dispersal in the Amazonian understory herb Heliconia acuminata. Mol. Ecol. 22, 5716-5729 (2013).

30. Trapnell, D. W., Hamrick, J. L., Ishibashi, C. D. \& Kartzinel, T. R. Genetic inference of epiphytic orchid colonization; it may only take one. Mol. Ecol. 22, 3680-3692. https://doi.org/10.1111/mec.12338 (2013).

31. Chung, M. Y. et al. Fine-scale genetic structure in populations of the spring ephemeral herb Megaleranthis saniculifolia (Ranunculaceae). Flora Morphol. Distrib. Funct. Ecol. Plants 240, 16-24 (2018).

32. Roberts, N. R., Dalton, P. J. \& Jordan, G. J. Epiphytic ferns and bryophytes of Tasmanian tree-ferns: A comparison of diversity and composition between two host species. Austral Ecol. 30(2), 146-154. https://doi.org/10.1111/j.1442-9993.2005.01440.x (2005).

33. Cardelús, C. L. \& Chazdon, R. L. Inner-crown microenvironments of two emergent tree species in a lowland wet forest. Biotropica 37(2), 238-244. https://doi.org/10.1111/j.1744-7429.2005.00032.x (2005).

34. Quaresma, A. C., Piedade, M. T. F., Wittmann, F. \& ter Steege, H. Species richness, composition, and spatial distribution of vascular epiphytes in Amazonian black-water floodplain forests. Biodivers. Conserv. 27(8), 1981-2002. https://doi.org/10.1007/ s10531-018-1520-3 (2018)

35. Claver, F. K., Alaniz, J. R. \& Caldíz, D. O. Tillandsia spp.: Epiphytic weeds of trees and bushes. For. Ecol. Manag. 6(4), 367-372. https://doi.org/10.1016/0378-1127(83)90044-0 (1983).

36. Bartoli, C. G., Beltrano, J., Fernández, L. V. \& Caldíz, D. O. Control of the epiphytic weeds Tillandsia recurvata and Tillandsia aeranthos with different herbicides. For. Ecol. Manage. 59, 289-294 (1993).

37. Flores-Palacios, A., García-Franco, J. G. \& Capistrán-Barradas, A. Biomass, phorophyte specificity and distribution of Tillandsia recurvata in a tropical semi-desert environment (Chihuahuan Desert, Mexico). Plant Ecology and Evolution 148(1), 68-75 (2015).

38. Birge, W. I. The anatomy and some biological aspects of the "ball moss", Tillandsia recurvata, 1-24. L. Bull. Univ. Tex. 194(20) (1911).

39. Smith, L. B. \& Downs, R. J. Tillandsioideae (Bromeliaceae). In Flora Neotropica Monograph 14(2), 663-1492 (1977). 
40. Hewitt, G. M. (1996). Some genetic consequences of ice ages, and their role in speciation. Biological Journal of the Linnaean Society, 58(July), 247-276. Retrieved from papers3://publication/uuid/B9DB7D5E-D6AE-404C-BFFC-9F8133453294

41. McWilliams, E. Chronology of the Natural Range Expansion of Tillandsia recurvata (Bromeliaceae) in Texas. Contributions to Botany 15(2), 343-346 (1992).

42. Flores-Palacios, A., Barbosa-Duchateau, C. L., Valencia-Díaz, S., Capistrán-Barradas, A. \& García-Franco, J. G. Direct and indirect effects of Tillandsia recurvata on Prosopis laevigata in the Chihuahua desert scrubland of San Luis Potosi, Mexico. J. Arid Environ. 104, 88-95. https://doi.org/10.1016/j.jaridenv.2014.02.010 (2014).

43. Benzing, D. H. Bromeliaceae: Profile of an Adaptive Radiation (Cambridge University Press, 2000).

44. Benzing, D. H. Air Plants: Epiphytes and Aerial Gardens (Cornell University Press, 2012).

45. Foster, M. D. Blueprint of the jungle as depicted by the altitude of growth of the Bromeliadswith notes on the culture of certain tropical epiphytes. Bull. N. Y. Bot. Garden 46, 9-16 (1945).

46. Soltis, D. E., Gilmartin, A. J., Rieseberg, L. \& Gardner, S. Genetic variation in the epiphytes Tillandsia ionantha and T. recurvata (Bromeliaceae). Am. J. Bot. 74(4), 531-537 (1987).

47. Orozco-Ibarrola, O. A., Flores-Hernández, P. S., Victoriano-Romero, E., Corona-López, A. M. \& Flores-Palacios, A. Are breeding system and florivory associated with the abundance of Tillandsia species (Bromeliaceae)?. Bot. J. Linn. Soc. 177(1), 50-65. https://doi.org/10.1111/boj.12225 (2015).

48. Chilpa-Galván, N. et al. Seed traits favouring dispersal and establishment of six epiphytic Tillandsia (Bromeliaceae) species. Seed Sci. Res. https://doi.org/10.1017/S0960258518000247 (2018).

49. Southwood, T. \& Kennedy, C. Trees as islands. Oikos 41(3), 359-371. https://doi.org/10.2307/3544094 (1983).

50. Burns, K. C. Network properties of an epiphyte metacommunity. J. Ecol. 95(5), 1142-1151 (2007).

51. Trapnell, D. W., Hamrick, J. L. \& Nason, J. D. Three-dimensional fine-scale genetic structure of the neotropical epiphytic orchid, Laelia rubescens. Mol. Ecol. 13, 1111-1118 (2004).

52. Torres, E., Riofrío, M.-L. \& Iriondo, J. M. Complex fine-scale spatial genetic structure in Epidendrum rhopalostele: an epiphytic orchid. Heredity https://doi.org/10.1038/s41437-018-0139-1 (2018).

53. Victoriano-Romero, E., Valencia-Díaz, A., Toledo-Hernández, V. H. \& Flores-Palacios, A. Dispersal limitation of Tillandsia species correlates with rain and host structure in a central Mexican tropical dry forest. PLoS ONE 12(2), e0171614 (2017).

54. Martins, S. E. (2009). Flora fanerogâmica do estado de São Paulo. FAPESP: Instituto de Botânica.

55. Chaves, C. J. N., Dyonisio, J. C. J. C. \& Rossatto, D. R. D. R. Host trait combinations drive abundance and canopy distribution of atmospheric bromeliad assemblages. AoB Plants 8(October 2015), plw010. https://doi.org/10.1093/aobpla/plw010 (2016).

56. Epps, C. W. \& Keyghobadi, N. Landscape genetics in a changing world: Disentangling historical and contemporary influences and inferring change. Mol. Ecol. 24(24), 6021-6040. https://doi.org/10.1111/mec.13454 (2015).

57. Cushman, S. A., Shirk, A. \& Landguth, E. L. Separating the effects of habitat area, fragmentation and matrix resistance on genetic differentiation in complex landscapes. Landsc. Ecol. 27(3), 369-380. https://doi.org/10.1007/s10980-011-9693-0 (2012).

58. Jackson, N. D. \& Fahrig, L. Habitat amount, not habitat configuration, best predicts population genetic structure in fragmented landscapes. Landsc. Ecol. 31(5), 951-968. https://doi.org/10.1007/s10980-015-0313-2 (2016).

59. Grimm, V. \& Railsback, S. F. Individual-Based Modelling and Ecology (Princeton University Press, 2005).

60. Csilléry, K., Blum, M. G. B., Gaggiotti, O. E. \& François, O. Approximate Bayesian Computation (ABC) in practice. Trends Ecol. Evol. 25(7), 410-418. https://doi.org/10.1016/j.tree.2010.04.001 (2010).

61. Udupa, S. M. \& Baum, M. High mutation rate and mutational bias at (TAA)n microsatellite loci in chickpea (Cicer arietinum L.). Mol. Genet. Genom. 265(6), 1097-1103. https://doi.org/10.1007/s004380100508 (2001).

62. Anmarkrud, J. A., Kleven, O., Bachmann, L. \& Lifjeld, J. T. Microsatellite evolution: Mutations, sequence variation, and homoplasy in the hypervariable avian microsatellite locus HrU10. BMC Evol. Biol. 8(1), 1-10. https://doi.org/10.1186/1471-2148-8-138 (2008).

63. Marriage, T. N. et al. Direct estimation of the mutation rate at dinucleotide microsatellite loci in Arabidopsis thaliana (Brassicaceae). Heredity 103(4), 310-317. https://doi.org/10.1038/hdy.2009.67 (2009).

64. Bernal, R., Valverde, T. \& Hernández-Rosas, L. Habitat preference of the epiphyte Tillandsia recurvata (Bromeliaceae) in a semidesert environment in Central Mexico. Can. J. Bot. 83(10), 1238-1247 (2005).

65. Chaves, C. J. \& Rossatto, D. R. Unravelling intricate interactions among atmospheric bromeliads with highly overlapping niches in seasonal systems. Plant Biol. 22(2), 243-251 (2020).

66. Vekemans, X. \& Hardy, O. J. New insights from fine-scale spatial genetic structure analyses in plant populations. Mol. Ecol. 13(4), 921-935. https://doi.org/10.1046/j.1365-294X.2004.02076.x (2004).

67. Ward, S. Genetic analysis of invasive plant populations at different spatial scales. Biol. Invasions 8(3), 541-552. https://doi.org/ 10.1007/s10530-005-6443-8 (2006)

68. Pettengill, J. B., Briscoe Runquist, R. D. \& Moeller, D. A. Mating system divergence affects the distribution of sequence diversity within and among populations of recently diverged subspecies of Clarkia xantiana (Onagraceae). Am. J. Bot. 103(1), 99-109. https://doi.org/10.3732/ajb.1500147 (2016).

69. Atwater, D. Z., Fletcher, R. A., Dickinson, C. C., Paterson, A. H. \& Barney, J. N. Evidence for fine-scale habitat specialization in an invasive weed. J. Plant Ecol. 11(2), 189-199. https://doi.org/10.1093/jpe/rtw124 (2018).

70. Li, J. \& Dong, M. Fine-scale clonal structure and diversity of invasive plant Mikania micrantha H.B.K. and its plant parasite Cuscuta campestris Yunker. Biol. Invasions 11(3), 687-695. https://doi.org/10.1007/s10530-008-9283-5 (2009).

71. Ren, M. X., Cafasso, D., Cozzolino, S. \& Pinheiro, F. Extensive genetic differentiation at a small geographical scale: Reduced seed dispersal in a narrow endemic marsh orchid, Anacamptis robusta. Bot. J. Linn. Soc. 183(3), 429-438. https://doi.org/10.1093/ botlinnean/bow017 (2017).

72. Barluenga, M. et al. Fine-scale spatial genetic structure and gene dispersal in Silene latifolia. Heredity 106(1), 13-24. https://doi. org/10.1038/hdy.2010.38 (2011).

73. Charbonneau, A. et al. Weed evolution: Genetic differentiation among wild, weedy, and crop radish. Evol. Appl. https://doi.org/ 10.1111/eva.12699 (2018)

74. Sagnard, F., Oddou-Muratorio, S., Pichot, C., Vendramin, G. G. \& Fady, B. Effects of seed dispersal, adult tree and seedling density on the spatial genetic structure of regeneration at fine temporal and spatial scales. Tree Genet. Genomes 7(1), 37-48. https://doi.org/10.1007/s11295-010-0313-y (2011)

75. Counsens, R. \& Mortimer, M. Dynamics of Weed Populations (Cambridge University Press, 1995).

76. Loreau, M. et al. Unifying sources and sinks in ecology and Earth sciences. Biol. Rev. 88, 365-379 (2013).

77. dos Santos, L. S. et al. Generalized Allee effect model. Theory Biosci. 133, 117-124 (2014).

78. Spruch, L. et al. Modeling community assembly on growing habitat "islands": A case study on trees and their vascular epiphyte communities. Theor. Ecol. 12, 1-17 (2019).

79. Einzmann, H. J. R. \& Zotz, G. "No signs of saturation": long-term dynamics of vascular epiphyte communities in a humanmodified landscape. Biodivers. Conserv. 26, 1393-1410 (2017).

80. Belinchón, R., Harrison, P. J., Mair, L., Várkonyi, G. \& Snäll, T. Local epiphyte establishment and future metapopulation dynamics in landscapes with different spatiotemporal properties. Ecology 98(3), 741-750. https://doi.org/10.1002/ecy.1686 (2017).

81. Vergara-Torres, C. A., Pacheco-Álvarez, M. C. \& Flores-Palacios, A. Host preference and host limitation of vascular epiphytes in a tropical dry forest of central Mexico. J. Trop. Ecol. 26(6), 563-570. https://doi.org/10.1017/S0266467410000349 (2010). 
82. Barrett, S. C. H. \& Kohn, J. R. Genetic and evolutionary consequences of small population size in plants: Implications for conservation. In Genetics and Conservation of Rare Plants (eds Falk, D. A. \& Holsinge, K. E.) 3-30 (Oxford University Press, 1991).

83. Nathan, R., Horn, H. S., Chave, J. \& Levin, S. A. Mechanistic models for tree seed dispersal by wind in dense forests and open landscapes. In Seed Dispersal and Frugivory-Ecologie, Evolution, Conservation 69-82 (2002). https://doi.org/10.1079/9780851995 250.0069

84. Cousens, R. et al. Dispersal in Plants. A Population Perspective (Oxford University Press, 2008).

85. Snäll, T., Ehrlén, J. \& Rydin, H. Colonization-extinction dynamics of an epiphyte metapopulation in a dynamic landscape. Ecology 86(1), 106-115 (2005).

86. Ruiz-Cordova, J. P., Toledo-Hernández, V. H. \& Flores-Palacios, A. The effect of substrate abundance in the vertical stratification of bromeliad epiphytes in a tropical dry forest (Mexico). Flora Morphol. Distrib. Funct. Ecol. Plants 209(8), 375-384. https://doi. org/10.1016/j.flora.2014.06.003 (2014).

87. Flores-Palacios, A., Bustamante-Molina, A. B., Corona-López, A. M. \& Valencia-Díaz, S. Seed number, germination and longevity in wild dry forest Tillandsia species of horticultural value. Scientia Hortic. 187, 72-79 (2015).

88. Goodman, R., \& Herold, M. (2014). Why maintaining tropical forests is essential and urgent for a stable climate. Center for Global Development Working Paper, (385).

89. Seymour, F. \& Busch, J. Why Forests? Why Now?: The Science, Economics, and Politics of Tropical Forests and Climate Change (Brookings Institution Press, 2016).

90. Stephenson, N. L. et al. Rate of tree carbon accumulation increases continuously with tree size. Nature 507(7490), 90-93 (2014).

91. Tel-Zur, N., Abbo, S., Myslabodsky, D. \& Mizrahi, Y. Modified CTAB procedure for DNA isolation from epiphytic cacti of genera Hylocereus and Selenicereus (Cactaceae). Plant Mol. Biol. Rep. 17, 249-254 (1999).

92. Chaves, C. J. N., Aoki-Gonçalves, F., Leal, B. S. S., Rossatto, D. R. \& Palma-Silva, C. Transferability of nuclear microsatellite markers to the atmospheric bromeliads Tillandsia recurvata and T. aeranthos (Bromeliaceae). Braz. J. Bot. 41, 931-935. https:// doi.org/10.1007/s40415-018-0494-4 (2018)

93. Keenan, K., Mcginnity, P., Cross, T. F., Crozier, W. W. \& Prodöhl, P. A. DiveRsity: An R package for the estimation and exploration of population genetics parameters and their associated errors. Methods Ecol. Evol. https://doi.org/10.1111/2041-210X.12067 (2013).

94. Slatkin, M. A measure of population subdivision based on microsatellite allele frequencies. Genetics 139, 457-462 (1995).

95. Nei, M. Genetic distances between populations. Am. Nat. 106, 283-292 (1972).

96. Edwards, A. W. F. Distance between populations on the basis of gene frequencies. Biometrics 27, 873-881 (1971).

97. Reynolds, J. B., Weir, B. S. \& Cockerham, C. C. Estimation of the coancestry coefficient: Basis for a short-term genetic distance. Genetics 105, 767-779 (1983).

98. Kamvar, Z. N., Tabima, J. F. \& Grünwald, N. J. Poppr: An R package for genetic analysis of populations with clonal, partially clonal, and/or sexual reproduction. PeerJ https://doi.org/10.7717/peerj.281 (2014).

99. Paradis, E. pegas: an R package for population genetics with an integrated-modular approach. Bioinformatics 26, 419-420 (2010).

100. Excoffier, L., Smouse, P. E. \& Quattro, J. M. Analysis of molecular variance inferred from metric distances among DNA haplotypes: Application to human mitochondrial DNA restriction data. Genetics 131, 479-491. https://doi.org/10.1007/s00424-0090730-7 (1992)

101. Loiselle, B. A., Sork, V. L., Nason, J. \& Graham, C. Spatial genetic structure of a tropical understory shrub, Psychotria officinalis (Rubiaceae). Am. J. Bot. 82(11), 1420-1425 (1995).

102. Bailleul, D., Stoeckel, S. \& Arnaud-Haond, S. RClone: A package to identify MultiLocus Clonal Lineages and handle clonal data sets in r. Methods Ecol. Evol. 7(8), 966-970. https://doi.org/10.1111/2041-210X.12550 (2016).

103. Harrison, S. et al. Beta diversity on geographic gradients in Britain. J. Anim. Ecol. 61(1), 151-158 (1992).

104. Jost, L. Partitioning diversity into independent alpha and beta components. Ecology 88(10), 2427-2439. https://doi.org/10.1890/ 07-1861.1 (2007).

105. Charney, N. \& Record, S. Vegetarian: Jost diversity measures for community data. https://cran.r-project.org/web/packages/veget arian/index.html (2012). Accessed Jul 2018.

106. Wilensky, U. NetLogo (Northwestern University, Center for Connected Learning and Computer-Based Modeling, 1999).

107. Grimm, V. et al. A standard protocol for describing individual-based and agent-based models. Ecol. Model. 198(1-2), 115-126. https://doi.org/10.1016/j.ecolmodel.2006.04.023 (2006).

108. Grimm, V. et al. The ODD protocol: A review and first update. Ecol. Model. 221(23), 2760-2768. https://doi.org/10.1016/j.ecolm odel.2010.08.019(2010)

109. Kooijman, B. \& Kooijman, S. A. L. M. Dynamic Energy Budget Theory for Metabolic Organisation (Cambridge University Press, 2010).

110. Sibly, R. M. et al. Representing the acquisition and use of energy by individuals in agent-based models of animal populations. Methods Ecol. Evol. 4(2), 151-161 (2013).

111. Johnston, A. S. A., Hodson, M. E., Thorbek, P., Alvarez, T. \& Sibly, R. M. An energy budget agent-based model of earthworm populations and its application to study the effects of pesticides. Ecol. Model. 280, 5-17 (2014).

112. van der Vaart, E., Johnston, A. S. A. \& Sibly, R. M. Predicting how many animals will be where: How to build, calibrate and evaluate individual-based models. Ecol. Model. 326, 113-123 (2016).

113. Garza, J. C. \& Williamson, E. G. Detection of reduction in population size using data from microsatellite loci. Mol. Ecol. 10, 305-318 (2001).

114. Excoffier, L., Laval, G. \& Schneider, S. Arlequin (version 3.0): An integrated software package for population genetics data analysis. Evol. Bioinform. Online 1, 47-50 (2005).

115. Csilléry, K., François, O. \& Blum, M. G. abc: An R package for approximate Bayesian computation (ABC). Methods Ecol. Evol. 3(3), 475-479 (2012).

116. Pastur, G. M., Lencinas, M. V., Cellini, J. M. \& Mundo, I. Diameter growth: Can live trees decrease?. Forestry 80(1), 83-88. https:// doi.org/10.1093/forestry/cpl047 (2007)

\section{Acknowledgements}

This research is part of the first author's thesis and was supported by resources supplied by the Center for Scientific Computing (NCC/GridUNESP) from São Paulo State University (UNESP). We thank A. Santos for computing support and S. Kakazu and M. Bacci for genotyping procedures. C.J.N.C received Ph.D. scholarships from CAPES and FAPESP (2016/04396-4; BEPE 2017/01559-2); B.S.S.L was funded by FAPESP (2014/080870); D.R.R. and C.P.S. were funded by Conselho Nacional de Desenvolvimento Científico e Tecnológico (CNPq 471756/ 2013-0 and 300819/2016-1, respectively). We also thank X. Picó and other three anonymous reviewers for providing helpful suggestions on earlier drafts of the manuscript. 


\section{Author contributions}

C.J.N.C. conceived and designed the research, designed the IBM, proceeded and analyzed the empirical and simulated data, and wrote the draft manuscript. B.S.S.L. contributed to the simulated analysis and discussion. B.S.S.L. and C.P.S. contributed to empirical study and discussion. D.R.R. contributed to the empirical material collection and design. U.B. contributed to the model conception. All authors contributed to manuscript revision, read, and approved the submitted version.

\section{Competing interests}

The authors declare no competing interests.

\section{Additional information}

Supplementary Information The online version contains supplementary material available at https://doi.org/ 10.1038/s41598-021-99798-5.

Correspondence and requests for materials should be addressed to C.J.N.C.

Reprints and permissions information is available at www.nature.com/reprints.

Publisher's note Springer Nature remains neutral with regard to jurisdictional claims in published maps and institutional affiliations.

(c) (i) Open Access This article is licensed under a Creative Commons Attribution 4.0 International License, which permits use, sharing, adaptation, distribution and reproduction in any medium or format, as long as you give appropriate credit to the original author(s) and the source, provide a link to the Creative Commons licence, and indicate if changes were made. The images or other third party material in this article are included in the article's Creative Commons licence, unless indicated otherwise in a credit line to the material. If material is not included in the article's Creative Commons licence and your intended use is not permitted by statutory regulation or exceeds the permitted use, you will need to obtain permission directly from the copyright holder. To view a copy of this licence, visit http://creativecommons.org/licenses/by/4.0/.

(c) The Author(s) 2021 